\title{
ГЕРНИОПЛАСТИКА БИОКАРБОНОВЫМ ИМПЛАНТАТОМ ПРИ БОЛЬШИХ ДИАФРАГМАЛЬНЫХ ГРЫЖАХ
}

\section{HERNIOPLASTY WITH BIOCARBONIC IMPLANT FOR LARGE DIAPHRAGMAL HERNIA}

\section{Rosenfeld}

Summary. In this research work, the results of a two-layer laparoscopic hernioplasty for large hiatal hernias using a medical biocarbon implant were described. The long-term results of a randomized study on surgical treatment of large diaphragmatic hernias with a defect area of 10-20 $\mathrm{cm} 2$ were analyzed. From 2014 to 2020, 92 patients were operated on. During the operations, the patients were divided into 2 research groups: 46 patients underwent laparoscopic plasty of diaphragmatic hernias by posterior cruroraphy (group I), other 46 patients underwent plasty with an Ultrapro biocarbon implant (Ethicon) according to the developed method (group II).

Keywords: diaphragmatic hernia, hernioplasty, biocarbon implant, cruraphia, operation technique.

\section{Ввехение}

$\mathbf{H}$ астоящая работа представляет собой часть рандомизированного исследования, которое было проведено с 2014 по 2020 год в рамках изучения оптимальной хирургической методики оперирования больших диафрагмальных грыж [1-3].

Целью настоящего исследования является рассмотрение анализа результатов оперирования больших грыж методом крурорафии в сравнении с применением конструкции из медицинского биокарбона.

Материалы и методы исследования. Была применена исследовательская гипотеза, что при больших диафрагмальных грыжах с площадью дефекта 10-20 см² (I, II и III) типов способ двухслойной пластики с использованием биокарбонового имплантата является более эффективным в плане профилактики анатомических рецидивов по сравнению с задней крурорафией, и сравнимой с ней по безопасности в плане частоты осложнений со стороны пищевода.

Дизайн исследовательской работы соответствовал международным требованиям, а именно, клиническим рекомендациям «EAES» - «The European association
Розенфельд Игорь Игоревич

К.м.н., врач-хирург, ФГБОУ ВО «Тверской ГМУ» МЗ РФ

iiggo@mail.ru

Аннотация. В данной исследовательской работе были последовательного описаны результаты проведения двухслойной лапароскопической герниопластики при больших грыжах пищеводного отверстия диафрагмы с применением имплантата из медицинского биокарбона. Проанализированы отдалённые результаты рандомизированного исследования по оперативному лечению больших диафрагмальных грыж с площадью дефекта в 10-20 см2. С 2014 по 2020 год было прооперировано 92 пациента. В ходе операций больные были разделены на 2 исследовательские группы: 46 пациентам применялась лапароскопическая пластика диафрагмальных грыж методом задней крурорафии (I группа), другим 46 больным — пластика биокарбоновым имплантатом «Ultrapro» («Ethicon») по разработанной методике (II группа).

Ключевые слова: диафрагмальные грыжи, герниопластика, биокарбоновый имплантат, крурорафия, техника операции.

for endoscopic surgery» («Европейская ассоциация эндоскопической хирургии») и “CONSORT - 2010»«Consolidated standards of reporting trials» («Консолидированные стандарты отчётных испытаний»).

Проведённое исследование было с применением параллельных групп: по ходу отбора больных относили к одной из групп. В работе использовалось двойное ослепление: ни больной, ни врач, проводивший обработку данных, не обладал информацией, каким именно способом осуществлялась герниопластика диафрагмального грыжевого дефекта.

Метод двойного ослепления был сделан путём присвоения каждому хирургическому больному случайного номера в ходе рандомизации, после этого обработка данных отдалённых результатов проводилась с учётом одной электронной таблицы и под обязательными случайными номерами. Далее после завершения исследования отдалённых результатов все данные разделялись на 2 группы и анализировались. После чего исследователь сопоставлял со случайными номерами персональные данные больных. Метод ослепления для больных обсуждался в добровольном информированном согласии, которое соответствовало международным требованиям, а также было одобрено этическим комитетом. 
В конце завершения исследования, пациентам было сообщено, каким именно методом им была выполнена герниопластика диафрагмального грыжевого дефекта.

Рандомизированное исследование было проведено следующим образом. С использованием генератора случайных неповторяющихся чисел создавалась таблица с цифрами от 1 до 100 по исходному количеству больных. Было сделано 100 одинаковых закрытых конвертов, в 50 - задняя крурорафия, а в остальных 50 - герниопластика двухслойным биокарбоновым имплантатом. Все конверты перетасовывались. Если в процессе отбора по предоперационным критериям больной исключался из научного исследования, то один из конвертов изымался и не использовался, а один из номеров, таким образом, в таблице случайных чисел вычёркивался. Для того, чтобы было осуществлено равномерное изъятия конвертов с целью предоставления одинаковых шансов для больных, также изымался конверт согласно противоположной методике. При выполнении оперативного вмешательства проводился заключительный отбор по интраоперационным критериям, например, по площади грыжевого диафрагмального дефекта. Если больной включался в исследование, то открывался любой из конвертов, далее объявлялась и выполнялась соответствующая операция. Таким образом, исследователь до последнего момента не знал, какая именно хирургическая операция будет выполнена, что тоже дополнительно исключало смещение в данном исследовании. Далее пациенту присваивался случайный номер из таблицы случайных чисел, который использовался при дальнейшей обработке его данных в электронном варианте. Из электронной таблицы случайных чисел эту цифру вычёркивали [4].

Рандомизированное проспективное исследование относилось к исследованиям III фазы: имплантат из медицинского биокарбона прошёл клинические испытания, которые доказали его безопасность. Кроме того, имелся собственный опыт использования данной конструкции при диафрагмальных грыжах в более чем 200 случаях без существенных осложнений. Проведённая исследовательская работа уточняет показания, а также противопоказания к применению биокарбонового имплантата.

Данный способ герниопластики выполняется следующим образом:

1. Выделяются края пищеводного отверстия диафрагмы, выполняется пластика этого грыжевого дефекта. Биокарбоновый имплантат длиной от 3-х до 9 см, шириной от 3-х до 7 см сгибают таким образом, чтобы биокарбоновый слой был обращён внутрь. Далее конструкцию вводят в брюшную полость с использованием троакара, где имплантат самостоятельно расправляется за счёт упругости биокарбонового слоя.

2. Биокарбоновую конструкцию с использованием зажима размещают таким образом, чтобы верхняя часть имплантата была расположена около пищевода, а боковые стороны - у диафрагмальных ножек, нижняя часть размещается у их основания. Сетка полностью повторяет форму пищеводного отверстия, что позволяет легко без натяжения тканей выполнить пластику. При этом сетка конструкции благодаря биокарбону не претерпевает сморщивания и может изменять свои параметры по горизонтали за счёт гибкости биокарбона.

3. Затем накладываются два отдельных узловых шва: один сквозной через правую и левую диафрагмальные ножки, а второй на их основание. При этом применяются только нити из рассасывающегося материала.

4. После чего биокарбоновый имплантат растягивают максимально по горизонтали, благодаря чему достигается наибольшая площадь соприкосновения устройства с биологической ткаHЬю.

5. В послеоперационном периоде в течение 3 дней биокарбон принимает контуры биологической ткани и через месяц после рассасывания полигликолидного слоя образуется наноплёнка в месте проведения герниопластики. Наноплёнка удерживает ткани в необходимом положении, таким образом, защищая от развития анатомического рецидива [5].

Все исследованные пациенты были прооперированы несколькими бригадами хирургов, которые имели опыт лапароскопических операций по поводу диафрагмальных грыж и гастроэзофагеальной рефлюксной болезни.

В начале к рандомизированному проспективному исследованию было привлечено 100 пациентов с диафрагмальными грыжами I (скользящие), II (параэзофагеальные) и III (смешанные) типов по классификации Люциуса Хилла, прооперированных с 2014 по 2020 год. В ходе отбора больных было исключено 2 пациентов, которые не соответствовали критериям включения и исключения [6] (1 пациент с нарушением перистальтики пищевода, 1 пациентка в возрасте 83 лет), 2 больных отказались от участия в исследовании (1 пациентка - по семейным обстоятельствам, 1 пациент отказался от метода ослепления), 4 пациента не отвечали интраоперационным критериям отбора (площадь диафрагмального грыжевого дефекта оказалась не соответствовала диапазону 10-20 см²). 
Таким образом, 92 оставшихся больных были рандомизированы. Пациенты разделялись на 2 исследовательские группы: І группа - «задняя крурорафия» (46 пациентов); II группа - «герниопластика биокарбоновым имплантатом» (46 пациентов) [7].

Статистическая обработка полученных данных осуществлялась расчётом распределения признака $\mathrm{M} \pm \mathrm{m}$, где $\mathrm{M}$ - средняя арифметическая и $\mathrm{m}$ - средняя ошибка средней арифметической анализируемых показателей.

В I группе из 46 пациентов диафрагмальные грыжи I типа были у 38 пациентов (83,7\%), II типа - у 1 больной (2,1\%), III типа-у 7 пациентов (14,2\%). Кардиальные грыжи пищеводного отверстия диафрагмы были у 5 пациентов (12\%), фундальные - у 40 пациентов (84,8\%), корпоральные - у 1 пациентки (2,2\%). Средний возраст пациентов составил 46,7 \pm 15,3 (26-77) лет. Мужчин было 20 (40,3\%), женщин - 26 (59,7\%). Операционный риск по шкале «ASA» I класса был у 39 (83,6\%) пациентов, II класса - у 7 пациентов (16,4\%). Средний индекс массы тела составил $24,9 \pm 3,8(17,3-37,5)$ кг/м². Средняя площадь грыжевого дефекта пищеводного отверстия диафрагмы составила

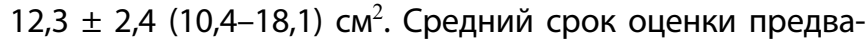
рительных результатов составил 6,3 \pm 0,7 (7-8) месяцев, отдалённых результатов - 24,6 \pm 0,9 (25-28) месяцев. По шкале «VAS» средний балл для рефлюксных симптомов составлял 5,8 \pm 2,4 (0-10) баллов, для болевого синдрома соответствовал 4,8 \pm 2,9 (0-10) баллов, для дисфагии - 0,7 $\pm 1,5$ (0-4) баллов, для внепищеводных симптомов - 1,5 \pm 3,1 (0-10) баллов. Внепищеводные симптомы были обнаружены у 11 пациентов (23,8\%): 5 пациентов с болями и (или) охриплостью в горле, 4 пациента с кашлем и (или) инспираторной одышкой, 1 пациент с сочетанием обоих видов указанных симптомов, 1 пациент с синусовой аритмией. Средний балл качества жизни пациентов по опроснику «GERD - HRQL» составил 19,1 \pm 8,1 (4-35) баллов $[8,9]$. По удовлетворенности состоянием распределение отмечалось следующим образом: частично удовлетворены - 15 пациентов (33,8\%), недовольны - 31 пациентов (66,2\%). По рефлюкс - эзофагиту согласно Лос - Анджелесской классификации распределение имело следующий вид: 0 степень была у 6 пациентов (14,2\%), степень A - у 24 пациентов (51\%), степень В - у 8 пациентов (18,6\%), степень C - у 6 пациентов (11,9\%), степень D у 2 пациентов (4,3\%). Средний индекс «De Meester», измеренный у 42 пациентов, составлял 90,7 \pm 57,4 (12,5-240,3). Среднее время пассажа рентгеноконтраста по пищеводу составило 3,9 \pm 1,4 (3-8) секунд.

Bo II группе из 46 пациентов диафрагмальные грыжи I типа отмечались у 42 больного $(90,1 \%)$, III типа - у 4 больных (9,9\%). При этом грыж II типа не наблюдалось. Кардиальные грыжи имели место у 5 больных $(9,7 \%)$, фундальные - у 39 пациентов (86\%), корпоральные - у 2 больных (4,3\%). Средний возраст больных составил $47,8 \pm 12,5$ (23-79) лет. Мужчин было 13 (27,1\%), женщин - 33 (72,9\%). Операционный риск по шкале «ASA» | класса отмечался у 36 пациентов (78,3\%), II класса у 10 больных (21,7\%). Средний индекс массы тела составил 23,4 \pm 4,8 (18,3-36,5) кг/м². Средняя площадь диафрагмального грыжевого дефекта составила 11,3 \pm 2,8 (10,3-19,3) см². Средний срок оценки предварительных результатов был 6,0 \pm 0,7 (5-8) месяцев, отдалённых результатов - 22,4 \pm 0,6 (22-26) месяцев. Средний балл по шкале «VAS» для рефлюксных симптомов составил $5,2 \pm 2,3$ (0-10) баллов, для болевого синдрома у больных $-5,1 \pm 2,6$ (0-10) баллов, для дисфагии - 1,1 $\pm 1,4$ (0-4) баллов, для экстрафагиальных симптомов - 1,6 \pm 2,8 (0-8) баллов. Внепищеводные симптомы отмечались у 12 пациентов (27,3\%): 7 пациентов с болями и (или) охриплостью, 3 пациента с пароксизмальным кашлем и (или) инспираторной одышкой, 2 больных с синусовой аритмией. Средний балл по опроснику «GERD - HRQL» составил 16,5 \pm 7,2 (4-35) баллов. По удовлетворённости состоянием распределение имело следующий вид: частично удовлетворены - 20 пациентов (44,7\%), недовольны - 26 пациентов (55,3\%). Степени рефлюкс эзофагита по Лос - Анджелесской классификации было следующим: 0 степень была у 8 пациентов (18,6\%), степень A - у 22 пациента (46,7\%), степень B - у 9 пациентов $(20,7 \%)$, степень C - у 7 пациентов (14\%), пациентов со степенью D не отмечалось. У 2 больных (4,3\%) обнаруживался короткий сегмент пищевода Барретта. Поскольку этим пациентам не была показана абляция, то они включались в исследование. Средний индекс «De Meester», который измерялся у 41 пациента, составил 90,1 \pm 62,6 (9,7-229,8). Среднее время пассажа рентгеноконтраста по пищеводу составило 4,8 \pm 1,6 (3-9) секунд.

\section{Результаты и обсужление}

В обеих исследовательских группах все оперативные вмешательства были выполнены успешно, интраоперационных осложнений не наблюдалось. Для статистической оценки использовался точный критерий Фишера, который в отличие от двухстороннего критерия мог использоваться для выборок с небольшим размером с высокой точностью.

Осложнения после операций наблюдались у 3-х пациентов (6,7\%) из I группы (ателектазы и лихорадка, которые относились к I степени по «Clavien - Dindo»), а также у 2 пациентов (4,3\%) из II группы (ателектазы и лихорадка, относящиеся к I степени по «Clavien Dindo»). Различий по частоте послеоперационных осложнений между группами достоверно не отличались (6,6 против 4,2\%; $p=0,5000)$. В среднем продолжительность оперативного вмешательства составила 60,5 $\pm 9,1$ (49-84) минут в I группе и 79, 1 × 11,8 (49-109) минут во II 
группе. По продолжительности операции была выявлена достоверная разница в пользу I группы $(60,5 \pm 9,1$ против 79,1 $\pm 11,8 ; p<0,0001$; критерий Манна - Уитни). Послеоперационный средний койко-день составил 5,7 \pm 1,6 (4-12) дней в I группе и 5,8 \pm 1,8 (4-10) дней во II группе. По послеоперационным койко-дням достоверных различий между группами не отмечалось $(5,7 \pm 1,6$ против 5,8 \pm 1,8; $p=0,9937 ;$ критерий Манна -Уитни).

Все хирургические операции в обеих группах были выполнены успешно. Случаи послеоперационных осложнений в исследовательских группах отмечались редко (без достоверного различия между группами) и относились к I степени по «Clavien - Dindo». По продолжительности операции была выявлена достоверная разница между группами.

По итоговым показателям, по частоте анатомических рецидивов всех видов наблюдалась достоверная разница в пользу II группы (15,5 против 2,4\%; $p=$ 0,0313). По частоте симптомных анатомических рецидивов и функциональных рецидивов достоверной разницы не отмечено (4,5 против 0,1\%; $p=0,2528)$. По частоте симптомных анатомических рецидивов разницы также достоверно выявлено не было (6,8 против 0,1\%; $p=0,1250)$. По частоте бессимптомных анатомических рецидивов и функциональных рецидивов достоверной разницы не отмечалось (2,3 против $0,1 \% ; p=0,505)$. По частоте бессимптомных анатомических рецидивов разницы не отмечалось (2,1 против 2,1\%; $p=0,7472)$. По частоте симптомных функциональных рецидивов разницы не отмечалось $(2,1$ против $2,1 \% ; p=0,7472)$. Функциональные бессимптомные рецидивы отсутствовали. По частоте функциональной дисфагии разницы также достоверно не обнаружено (2,1 против 4,2\%; $p$ $=0,4915)$. Стриктур пищевода не было. По частоте повторных оперативных вмешательств достоверной разницы выявлено не было (4,5 против 0,1\%; $p=0,2528)$.

Через 2 года после хирургических операций получена статистически достоверная разница в пользу II группы по среднему баллу шкалы «VAS» для рефлюксных симптомов и болевого синдрома, средним индексом «De Meester» и частотой анатомических рецидивов всех типов. В распределении по удовлетворённости общим состоянием разница была статистически достоверна в пользу II группы, то есть при выполнении герниопластики биокарбоновым имплантатом. По другим субъективным и объективным данным, а также итоговым показателям статистически достоверной разницы не отмечалось, в том числе по частоте осложнений со стороны пищевода. Было проведено сравнение начальных результатов между исследовательскими группами, что свидетельствует о возможности эффективного использования конструкции из биокарбона при любой мето- дике проведения оперативного вмешательства. Многие показатели, которые были выражены в баллах, среднее значение (М) отмечено меньше, чем ошибка среднего $(\mathrm{m})$, что свидетельствует об обратной зависимости изучаемого признака по вариабельности. При этом наличие даже незначительного показателя вероятности рецидива указывало на возможные перспективы совершенствования техники хирургической операции.

\section{Выво $\triangle \mathrm{b}$}

При сравнении непосредственных результатов оперативного лечения больших диафрагмальных грыж отмечено, что в обоих исследованиях все хирургические операции были выполнены успешно, а случаи осложнений после операций имели место без достоверного статистического различия между группами, а также относились к I степени по «Clavien - Dindo». Выявлена достоверная закономерная разница между исследовательскими группами по продолжительности хирургической операции. По субъективным и объективным данным, а также итоговым показателям через 2 года после операций достоверных различий между группами не отмечались, хотя и наметилась тенденция к увеличению частоты симптоматических анатомических рецидивов в I группе, то есть при выполнении задней крурорафии. За вес период наблюдения за пациентами серьёзных осложнений не отмечалось. Таким образом, возникает необходимость о продолжении данного рандомизированного проспективного исследования с изучением отдалённых результатов на следующем этапе.

В данной исследовательской работе предлагается концепция методики при больших диафрагмальных грыжах с использованием биокарбонового имплантата, которая снижает риск рецидивов, осложнений, а также болевого синдрома, что способствует повышению уровня жизни больных по сравнению с бесфиксационными методами герниопластики.

Данный метод может быть использован как для операций спереди, так и позади диафрагмальных ножек в зависимости от индивидуальных показателей больного с большими диафрагмальными грыжами без вариативного компонента, что достигается благодаря эффекту «интайм» при приращении биокарбонового имплантата к тканям пациента.

Предложенное техническое решение при выполнении герниопластики больших диафрагмальных грыж повышает надёжность хирургической операции благодаря использованию биокарбона, формирующего нанослой и позволяющего сократить количество послеоперационных осложнений благодаря его фиксации к диафрагмальным ножкам лишь в двух точках. 


\section{ЛИТЕРАТУРА}

1. Розенфельд И.И. Способ лапароскопической пластики больших и гигантских грыж пищеводного отверстия диафрагмы с использованием биокарбонового имплантата // Патент на изобретение № 2694216.

2. Розенфельд И.И., Чиликина Д.Л. Оценка результатов использования сетчатых имплантатов при аллопластике грыж пищеводного отверстия диафрагмы / Исследования и практика в медицине. — 2018. - Т. 5, № 4. — C. 82-90. doi: 10.17709/2409-2231-2018-5-4-8

3. Розенфельд И.И., Акопян В.А. Классификация негативных результатов лапароскопических операций при грыжах пищеводного отверстия диафрагмы // Материалы XII Международной научно-практической конференции и студентов и молодых учёных-медиков «Молодежь - практическому здравоохранению». - Тверь: ФГБОУ ВО Тверской ГмУ Минздрава России. Совет молодых учёных и студентов. — 2018. — C. 856-858.

4. Targarona E.M., Grisales S., Uyanik 0 . et al. Long-term outcome and quality of life after laparoscopic treatment of large paraesophageal hernia // World journal of surgery. — 2013.— Vol. 37. — № 8. — P. 1878-1882.

5. Furnée E. Hazebroek E. Mesh in laparoscopic large hiatal hernia repair: a systematic review of the literature // Surgical endoscopy. — 2013. — Vol. 27.— № 11. - P. 3998-4008.

6. Грубник В.В. Малиновский А.В. Критические аспекты лапароскопической хирургии гастроэзофагеальной рефлюксной болезни и грыж пищеводного отверстия диафрагмы // Одесса: ВМВ-типография.—-2015.- 106 с.

7. Granderath F.A., Schweiger U.M., Kamolz T. et al. Laparoscopic antireflux surgery with routine mesh-hiatoplasty in the treatment of gastroesophageal reflux disease // Journal of gastrointestinal surgery.— 2002.— Vol. 6. — № 3. - P. 347-353.

8. Antoniou S.A., Koch 0.0., Antoniou G.A. et al. Mesh-reinforced hiatal hernia repair: a review on the effect on postoperative dysphagia and recurrence // Langenbeck's archives of surgery. — 2012.—Vol. 397. — № 1.—P. $19-27$.

9. Frantzides C.T., Carlson M.A., Loizides S. et al. Hiatal hernia repair with mesh: a survey of SAGES members // Surgical endoscopy. — 2010. — Vol. 24. — № 5. - P. 1017-24.

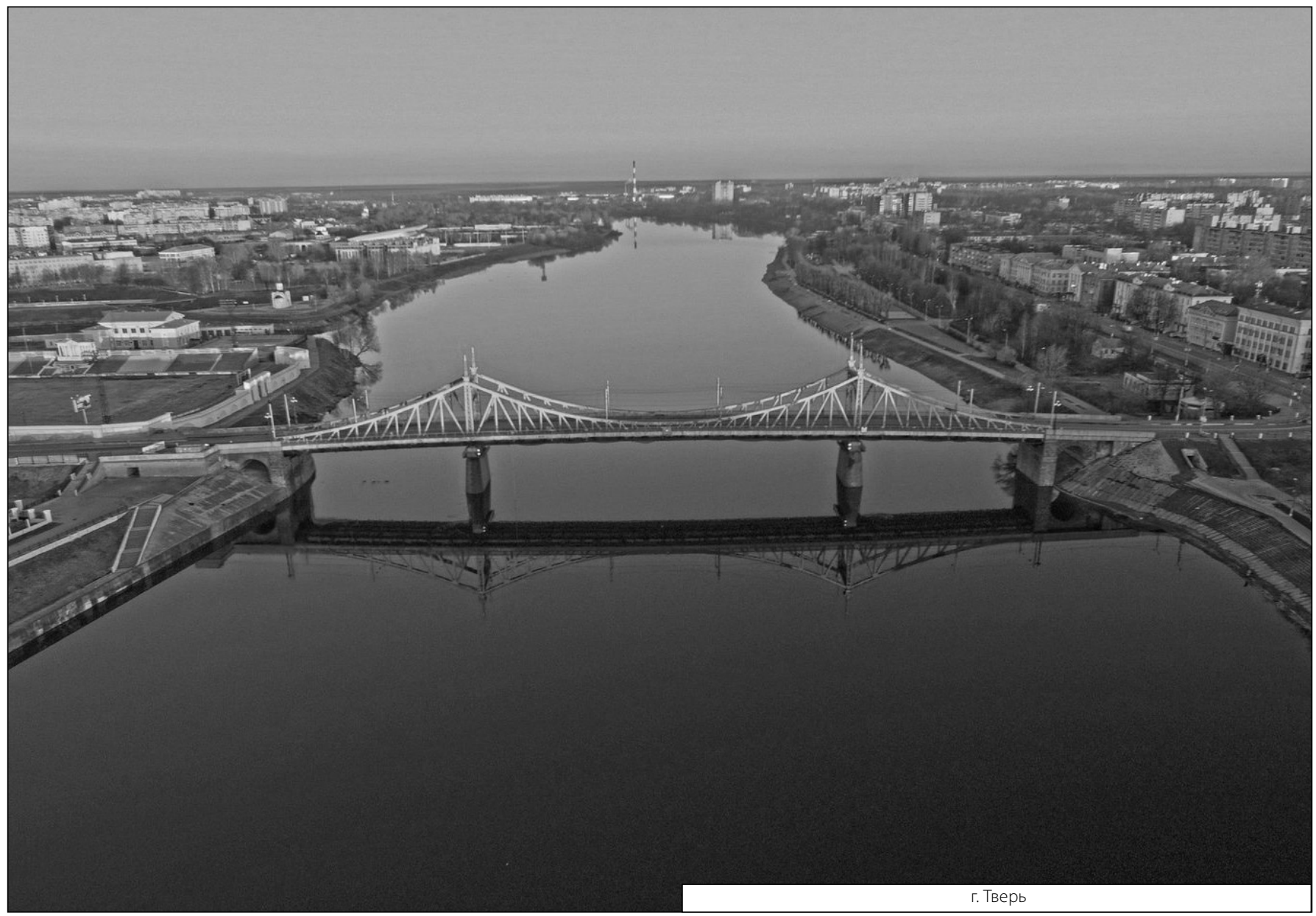

